\title{
Culture and the Scottish Household Survey
}

\author{
Vikki McCall and Christopher Playford \\ School of Applied Social Science, University of Stirling, Scotland \\ vikki.mccall@stir.ac.uk; c.j.playford@stir.ac.uk
}

In 2007 the Scottish Government introduced an outcomes based approach to culture set within a National Performance Framework. One of the main data sources to measure 'culture' in Scotland is the Scottish Household Survey (SHS). In this article the SHS and its 'Culture and Sport' Module are explored to show how useful the data is within the Scottish Government's economic agenda. This way, the paper reflects on the usefulness of the main data source used to understand cultural activity within Scotland. There are general difficulties measuring 'culture' but overall the SHS provides adequate national data for Scotland on cultural participation and attendance. However, the SHS cannot provide in-depth local level information and provides limited data on nonparticipants. Other surveys in Scotland and England give some example practices that could be incorporated to improve survey outcomes. Overall, the SHS is a useful policy tool but more could be done to utilise the data it can provide on the Scottish cultural sector.

Keywords: culture; cultural participation; Scottish Household Survey; Scottish Government policy; Scottish data sources

\section{Introduction}

One of the greatest challenges in the Scottish cultural policy sector involves providing evidence on cultural activity and demonstrating its links to current policy. The Scottish Household Survey (SHS) is a rich source of data for cultural information that provides a representative sample of participation and attendance of cultural activities within Scotland. It is one of the principle means of providing the evidence needed to show policy makers the importance of the cultural sector. This paper explores the Scottish Household Survey (SHS) and how useful it is as a policy tool. Exploring the SHS as a policy tool is especially important in the current Scottish context. In 2010 the Scottish Government began an internal review of the SHS. This review involved looking at current population surveys conducted and funded by the Scottish 
Government to create a central and long term strategy, full content review and redesign. Motivations include aligning topics and questions with the Scottish Government's policy vision for Scotland (outlined in their National Performance Framework). This is because "the Scottish Government sees culture as a cross-cutting tool which can potentially contribute to the Government's Purpose and all of the National Outcomes for Scotland, which are set out in the National Performance Framework" (Scottish Government, 2009a, p.6, original emphasis). Within the context of the SHS, ideas of 'culture' relate to Scotland's cultural participation and attendance in what is termed the cultural sector. This paper explores what this entails for 'culture', which is a topic not explicitly incorporated into the Scottish Government's high-level aims and outcomes within the National Performance Framework (NPF). It does this by firstly showing what the SHS tells us about 'culture', followed by an exploration of how adequate this data is in assessing its contribution to the National Performance Framework (NPF). Finally, some conclusions are drawn around the SHS and its contribution to Scotland's cultural policy strategy.

\section{Culture and the Main Scottish Household Survey Data}

The Scottish Household Survey has been running since 1999 and has informed government publications as well as other reports that have varied from the analysis of unpaid carers in Scotland (Harkins et al,. 2006), to financial inclusion (Hayton et al., 2007) and volunteering (Hurley et al., 2008). Other topics that are covered include transport, housing and social justice as well as culture and sport in Scotland. The stated aims of the survey are:

- To provide household and individual information particularly to support the work of the Scottish Government's transport, communities and local government policy areas and the work of the Scottish Parliament;

- To permit disaggregation of information both geographically and in terms of population sub-groups (such as families with children or the elderly);

- To allow the relationships between social variables within households to be examined. This will support cross-analysis on a range of issues; 
- To allow early detection of national trends;

- To allow detailed follow-up surveys of sub-samples from the main survey sample, if required (Scottish Government, 2009b).

The aims highlight the potential of the SHS to be a significant policy tool for many sectors. For culture in particular, the 'Culture and Sport' Module was added in 2007 as a large subsection within the SHS. The main publications around culture and sport include People and Culture in Scotland 2007 and 2008, which were commissioned with the specific aim of informing Scottish cultural policy (Scottish Government, 2008a, 2009a, 2009b, 2009c). These highlighted the extent of Scottish adults' participation in cultural activities and events, showing its importance by highlighting that $72 \%$ of those surveyed had taken part in some form of cultural activity in the year 2008 (Scottish Government, 2009b). The SHS remains the main source of evidence used by the Scottish Government to analyse cultural services and inform cultural policy.

There is, however, a gap in analysis of the SHS as a key source of data for the cultural sector. Furthermore, critics in this sector already question the quality of cultural data and what help it can provide cultural services (Selwood, 2002; Madden, 2005; Belfiore \& Bennet, 2007). It is important to fill these gaps as the SHS constitutes the main source of information used by the Scottish Government to inform and shape its cultural policy. It is thus a potentially important tool in assessing the contribution of the cultural sector to the Scottish policy agenda. This section firstly examines what the main survey data tells us to help explore the extent to which the SHS is capable of insights for policy and cultural services.

\section{The SHS Main Survey Data}

This section outlines some reported and modified indicators of participation using SHS data from the main section of the survey. Examples of certain under-represented, socio-economic groups are used as they have been identified by the NPF. The examples below highlight significant effects on cultural participation when adjusting for certain activities. This helps to highlight what the SHS can tell us about the extent 
of cultural participation and attendance in Scotland that may be of interest to policymakers.

One of the main strengths of the SHS is its size compared to other studies, such as that conducted by the Scottish Arts Council, and has a more robust methodology ${ }^{1}$. As a whole, the SHS main section contains general information collected on all topics. The SHS 'Culture and Sport Module' is a subset of extra questions with greater detail on culture and sport (these are henceforth referred to as the 'main' section and the 'Module'). Broad and specific indicators ${ }^{2}$ of cultural participation and attendance within the last 12 months (and how often these were undertaken) are recorded in the main section of the SHS (for more details of sampling please see note 1 at the end of this paper). This section concentrates on the headline statistics for participation, namely those that refer to participation in any activity. The full breakdown of these activities can be found in the main report to the SHS (Scottish Government 2009a, p.157, 166) where it can be seen that reading and cinema (the latter included in attendance data) are the largest response categories. The purpose of demonstrating these figures with the SHS data is to suggest how the SHS can be used by secondary data analysts (and policy makers) to clarify levels of participation, the third of the stated aims of the survey. However, the measure of participation in any activity may be misleading to policy makers if reading is considered a less important factor.

A series of outcome variables using the main SHS random adult sample are constructed in this paper as follows:

- Participation (excluding reading)

- Attendance (excluding cinema)

- Participation in multiple activities

- Attendance at multiple event types

In the main SHS report, the percentage participating in any cultural activity in the last 12 months is $67 \%$ for males and $77 \%$ for females (Scottish Government, 2009a).

\footnotetext{
${ }^{1}$ The SAC/Creative Scotland Taking Part survey is biennial and uses quota sampling method.

${ }^{2}$ For participation, the cultural activities a respondent could select from are: reading for pleasure, dance, crafts, played instrument/written music, art/sculpture, photography, computer artworks/animation, performance with audience, written stories etc, film/video, other cultural activity or none.
} 
When the figures are adjusted to exclude reading, these fall to $42 \%$ for males and $47 \%$ for females. This firstly highlights that reading (and this includes newspapers, fiction and non-fiction) is the largest form of cultural participation in the UK. Also, reading is more prevalent among women as the difference between the participation figures for men and women are reduced when adjusted for reading. Smaller numbers participate in multiple activities, with $34 \%$ for men and $41 \%$ for women. The greater resilience of the female percentage following the introduction of these controls suggests females are more omnivorous in their cultural activities than males. The inverse relationship between age and cultural participation appears to strengthen when reading is removed from the list of activities included, as it does when multipleparticipation is included. The reported participation figure for over $75 \mathrm{~s}$ is strongly influenced by reading or participation in a single activity (64\% of over 75 s participate in any activity, 24\% participate in any activity excluding reading and 19\% participate in multiple activities). Figure one demonstrates this: 
Figure 1: Participation in any cultural activity in the last 12 months by gender and age

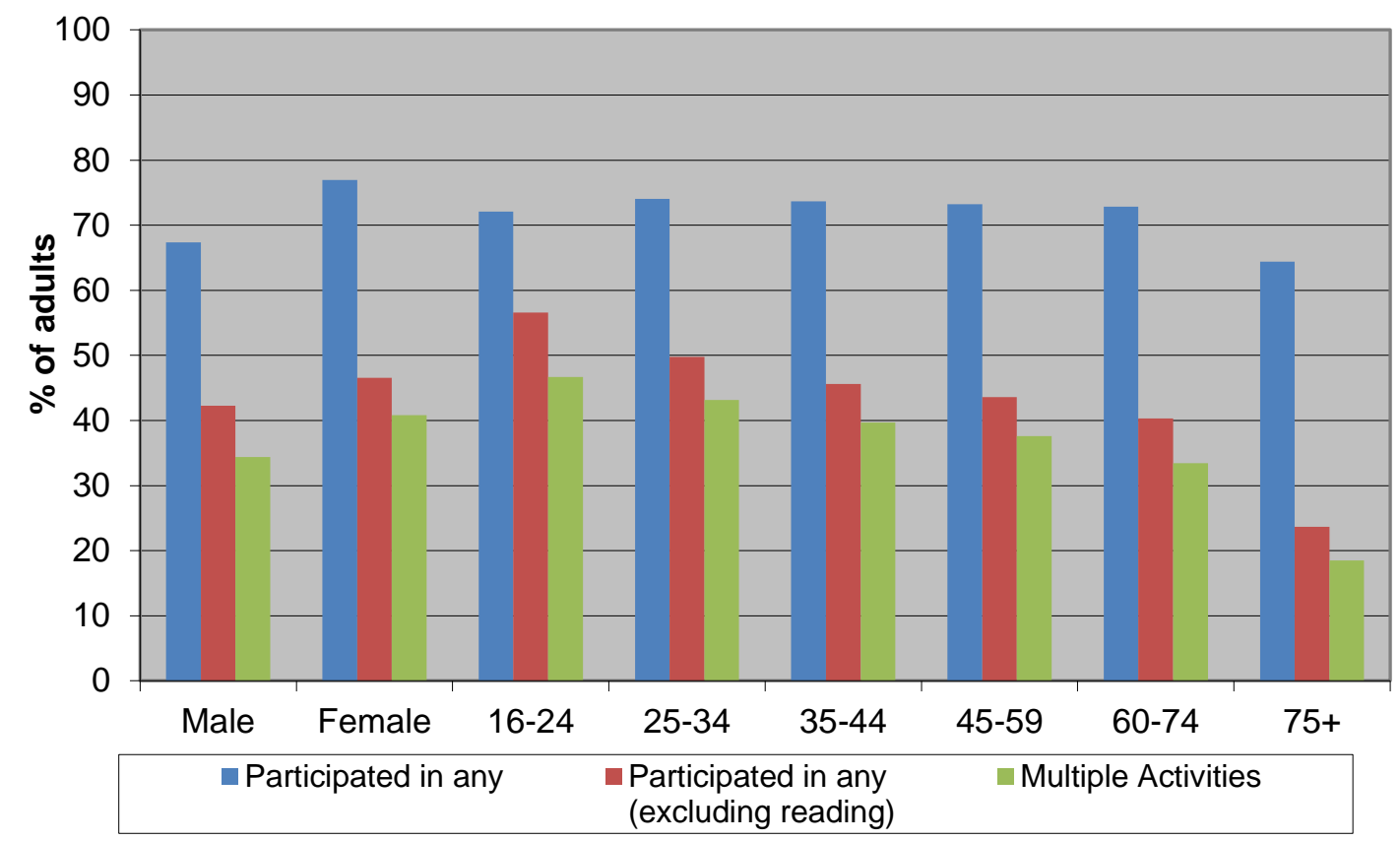

(Source SHS 2007/2008, Base 19,532)

Similarly, there is evidence that those with Higher Educational qualifications are more varied in their participation (see figure 2).

Figure 2: Participation in any cultural activity in the last 12 months by highest level of qualification

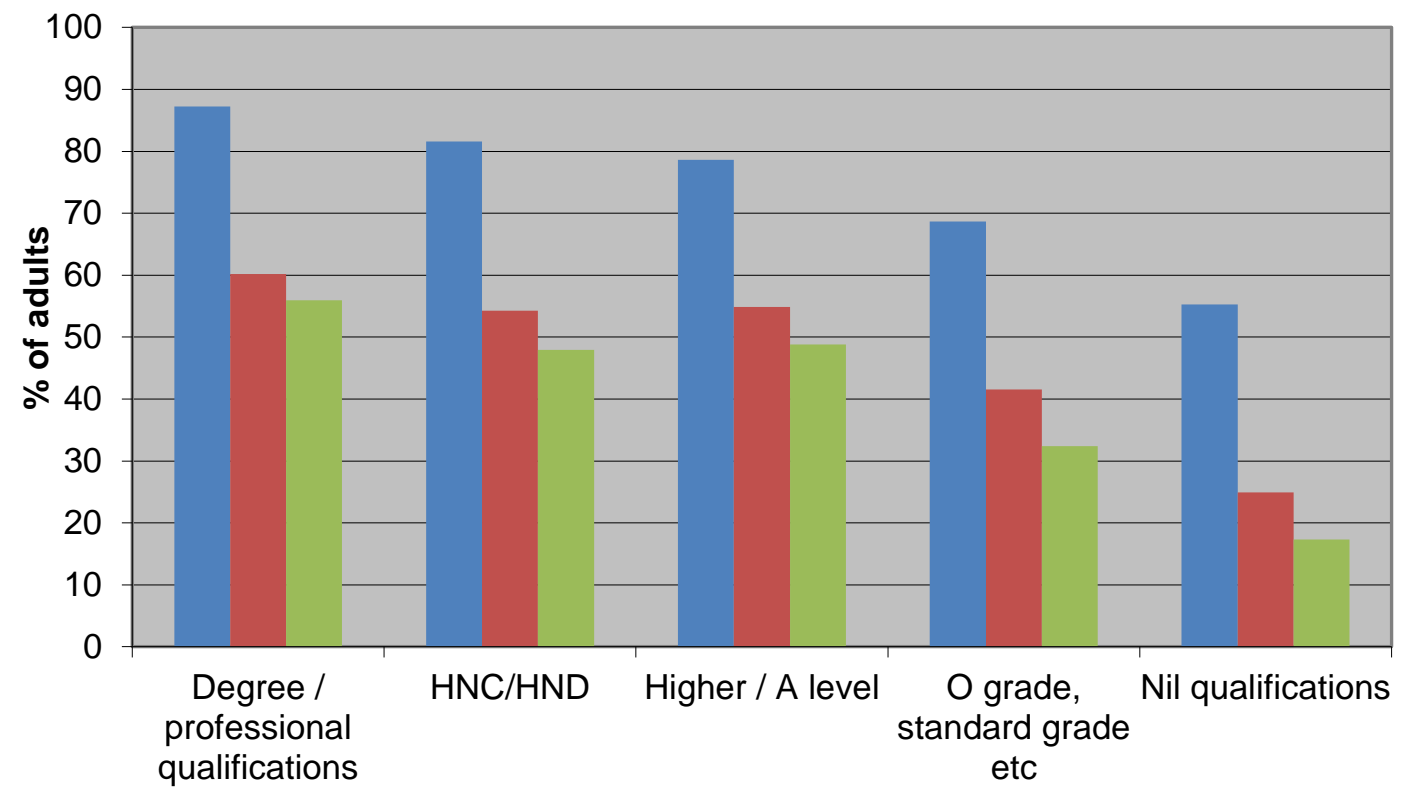

\begin{tabular}{|cc|}
\hline$\square$ Participated in any & $\begin{array}{l}\text { Participated in any } \\
\text { (excluding reading) }\end{array}$ \\
\hline
\end{tabular}


(Source SHS 2007/2008, Base 19,232)

The influence of the new outcomes when expressed by quintiles of the Scottish Index of Multiple Deprivation scale (SIMD) is fairly evenly distributed. This implies that participation (excluding reading) and participation in multiple activities are not differentially associated with $\mathrm{SIMD}^{3}$ (see figure 3). However, the negative association between participation (by any measure) and deprivation persists. It is possible that there are other dimensions which may be obscuring this, but from a simple two-way tabulation this is not apparent (for example different age structures within quintiles of SIMD).

Figure 3: Participation in any cultural activity in the last 12 months by Scottish Index of Multiple Deprivation

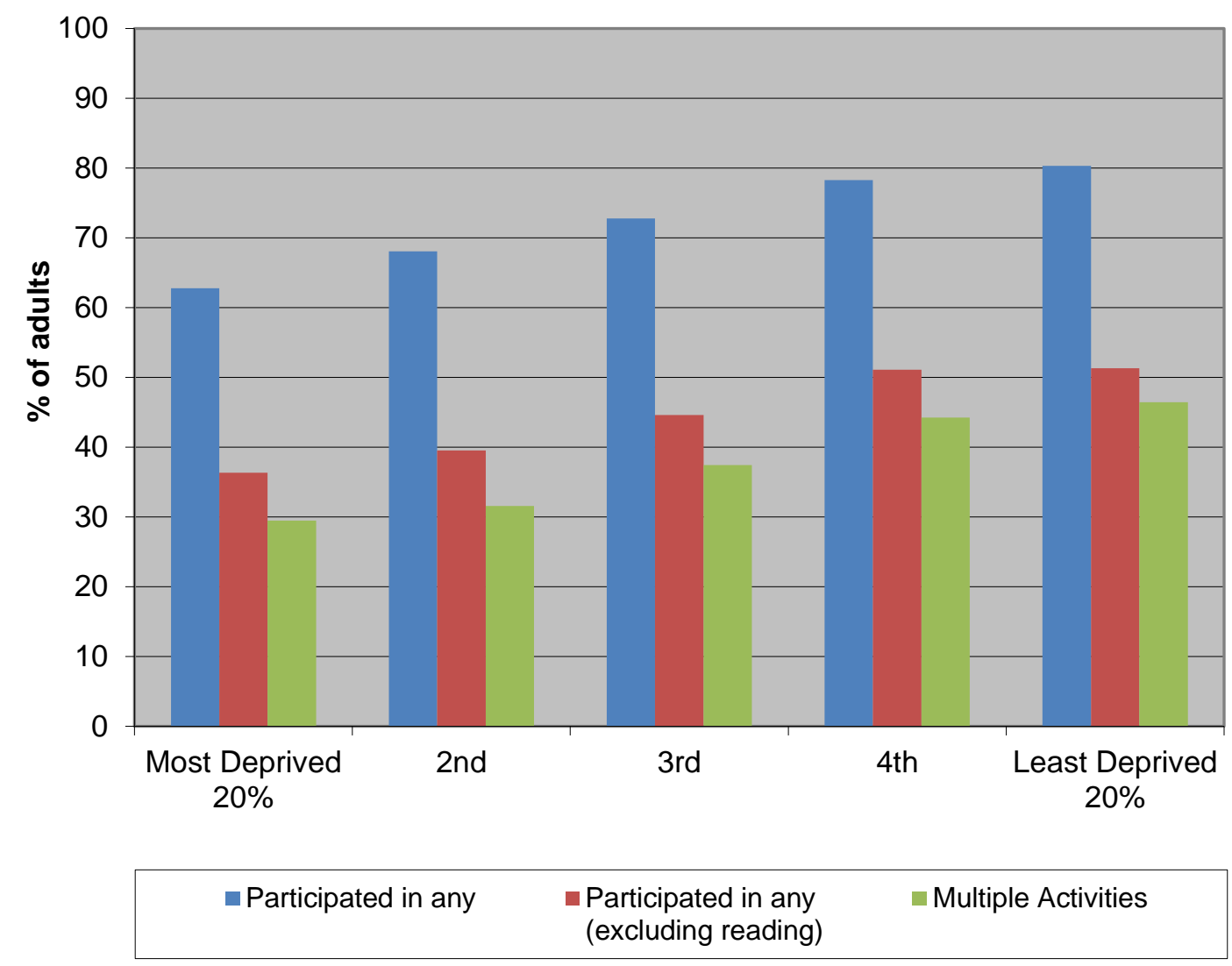

(Source SHS 2007/2008, Base 19,532)

\footnotetext{
${ }^{3}$ In addition to SIMD, National Statistics Socio-Economic Classification (NS-SEC) is recorded in the SHS (for further details see end note 2 )
} 
Another relevant indicator is rural and urban participation. Rural participation in cultural activities continues to be higher than urban participation using the new measures of participation, suggesting that people living in rural areas are more likely to participate (see figure 4). The weighting of estimates in the SHS should correct for any differences that might be due to clustered versus unclustered sampling in the rural and urban areas. Of those living in remote rural locations (in settlements of below 3,000 population and over 30 miles from an urban area), $79 \%$ participate in any activity. 53\% of this group participate in any activity (excluding reading) and $45 \%$ participate in multiple activities. The respective figures for those in urban settlements (with a population of over 125,000) are $73 \%, 45 \%$ and $38 \%$. Those living in other urban areas or small accessible towns are least likely to participate in activities (excluding reading) and least likely to participate in multiple activities.

Figure 4: Participation in any cultural activity in the last 12 months by rurality

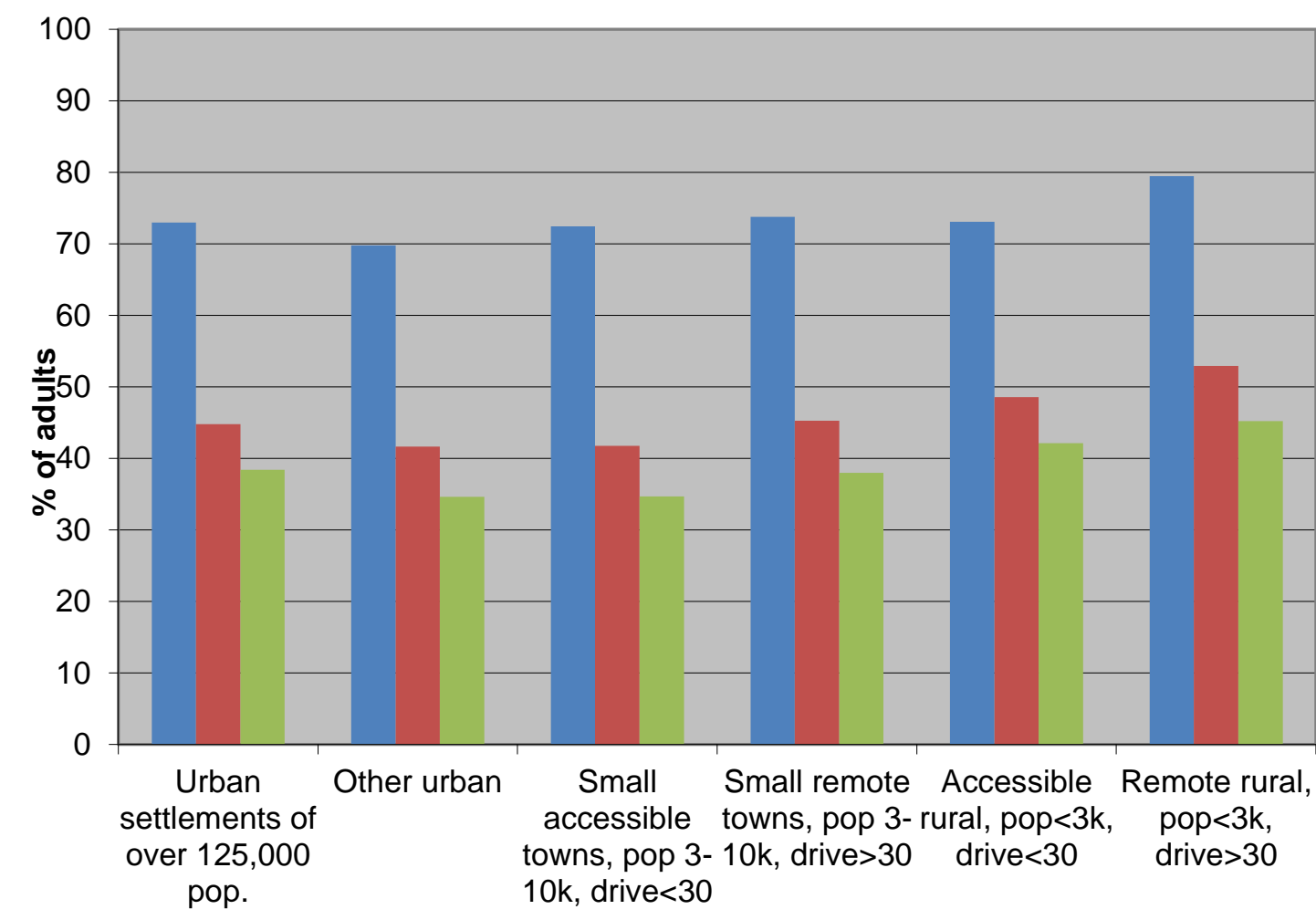


The figures presented here suggest a more conservative measure reflecting nonreading participation, which may be of use to policy makers. This section has demonstrated that the SHS can be used to demonstrate associations between cultural participation (using a range of measures) and gender, age, education, SIMD and rurality in Scotland. As already noted, the Scottish Government expects 'culture' to contribute and link to all government aims and objectives. The next section highlights the policy context in more detail to discuss how useful this knowledge is within current Scottish Government strategy.

\section{The contribution of the Scottish Household Survey to the Scottish Government's}

\section{Devolved Policy Approach}

The adequacy of the SHS as a policy tool can only be assessed in conjunction with an understanding of the Scottish policy context. This is important as this context is very different from the rest of the UK, with the Scottish Parliament having control over cultural policy since devolution in 1999. Since 2007 the Scottish National Party (SNP) have governed Scotland as firstly a minority then majority government ${ }^{4}$. During the process of changing the Scottish Executive into the Scottish Government, the SNP also realigned Scottish policy into an outcomes-focused approach. This approach has particular significance to local authorities within Scotland, who have been asked to form a 'new' relationship with central government by taking on more responsibility and risk in regards to policy making and delivery.

Central Government policy expectations are now set out in the National Performance Framework (NPF) (for details see the Scottish Budget Spending Review, 2007a). The Scottish Government Purpose is set out in the NPF and aims "to focus the Government and public services on creating a more successful country, with opportunities for all of Scotland to flourish, through increasing sustainable economic growth" (Scottish Government, 2007b). This purpose sits at the top of the Scottish Government's hierarchy of priorities and is followed by a set of strategic objectives and targets. Strategic objectives include Scotland becoming healthier, safer and stronger, smarter and greener. These are then followed by higher-level targets. The

\footnotetext{
${ }^{4}$ This paper was written before the May 2011 elections that brought in the Scottish National Party as a majority
} government in Scotland. 
participation target, for example, aims "to maintain our position on labour market participation as the top performing country in the UK and close the gap with the top 5 OECD economies by 2017" (Scottish Government, 2007b). These are then followed by fifteen national outcomes and forty-five indicators that give more detailed measures for local authorities to fulfil the Scottish Government's overall purpose. Further indicators have been added since 2007. It is a significantly different policy context from the rest of the UK and poses certain challenges for survey methods that were created before the outcomes-based approach was introduced.

The Scottish Governments aim was to simplify their goals and targets so that local authorities could have more freedom in creating their own local policies. Local authorities are free to outline their own local approaches as long as they can show they are feeding into the centralised vision outlined in the NPF. Perri (1996) shows examples of this type of outcomes-orientated government, where central government believe it is possible to integrate and focus policy networks to a central focus. This approach also shows an increase in 'steering' through policy decisions and less involvement in policy delivery, or 'rowing' (Osborne \& Gaebler, 1992, p.20). Rhodes (2000) points out that this top-down approach is a very difficult situation to control centrally. The Scottish Government is then taking an increased role in 'steering' rather than delivery through its outcomes-based approach. This is reflected more strongly through its agreements with local authorities that ensure that policy delivery is directed towards fulfilling the NPF. This increases the importance of providing robust evidence of policy delivery.

The new agreement between the Scottish Government and Scottish Local Authorities is set out in a Concordat agreement between the Scottish Government and CoSLA (see note 3 for more details at the end of the paper). This agreement includes the freedom to fulfil the NPF through local priorities, which are set out and agreed through Single Outcomes Agreements (SOAs). The SOA is "the means by which Community Planning Partnerships (CPPs) agree their strategic priorities for their local area and express those priorities as outcomes to be delivered by the partners, either individually or jointly, while showing how those outcomes should contribute to the Scottish Government's relevant National Outcomes" (SOA Guidance 5, Improvement Service, 2008b). The aim here is to allow local authorities to prioritise 
their local needs while at the same time fulfilling an overarching strategic vision for improvement throughout Scotland.

Thus the Scottish Government has not only introduced a new policy direction, but a move away from need-based, or resource based planning, to a focus on "the impact, or consequences for the community, of the activities of organisations or services over a number of years. Outcomes are the result of what you do, or what you enable communities to do for themselves, rather than descriptions of the activities or services you provide" (Information Services, 2008, original emphasis). What makes this significant is that activities are not single-target focused but integrated together with the ability to feed into several outcomes. The data shown within the main SHS survey has already outlined some of the links culture has with other topics. In this way, the SHS is useful for contributing evidence to an integrated policy agenda.

This integration of activities creates a more dynamic policy implementation process. Ultimately, however, it is a top-down policy process based on rational choice (Pressman \& Wildavsky, 1979; Hogwood \& Gunn, 1984; Sabatier, 1986). It is assumed that those taking action shall make the choices logically according to the benefits or losses involved. All action is presented as motivated by reason, for instrumental action (Scott, 2000). It is also a more instrumental policy, where the value of culture must be shown through measurable targets and outcomes (Orr, 2008). This paper has already shown that culture is indeed linked to many topics that feature in the NPF. However, this information is very general. This is both a challenge and opportunity to those sectors, such as the cultural sector, that do not feature in higherpriorities within the NPF (details of this are below). The data needs to provide specific evidence that integrates culture into the National Performance Framework. The current review of the SHS within the Scottish Government could provide the opportunity to cut out inadequate data to replace with new - outcomes focused measures that would help build the evidence base for culture. More details are given in the next section in regards to where culture specifically sits within the Scottish Government agenda. 


\section{Culture within the National Performance Framework}

As already mentioned, outcomes for culture are integrated into all NPF outcomes. The SHS has been shown to be able to provide high level links with education, health, SIMD, rural-urban divides and other measures. Information on cultural participation at a Scottish-level is particularly strong in the SHS. There is also a 'participation' target (although this refers to participation mainly in the labour market). However, more specifically within the NPF there is also a 'cultural participation' local outcome indicator, which is linked with National Outcome 13 "we take pride in a strong, fair and inclusive national identity" (Improvement Service, 2009). The local outcome is defined as:

"All those who answer as taking part in an activity from the list: dance; played a musical instrument or written music; rehearsed, performed or sang in front of audience, e.g. play or choir (not karaoke); painting, drawing, printmaking or sculpture; photography as an artistic activity) not family or holiday 'snaps'); made films or video as an artistic activity (not family or holidays); used a computer to create original artwork or animation; crafts such as textile, wood, pottery, etc.; read for pleasure (not newspapers, magazines or comics); written any stories, books, plays or poetry; other cultural activity; none. (other than none). The denominator is all random adults selected to answer question CULT1A (from the relevant LA)".

The current source of assessment for the cultural participation local outcome indicator is the Scottish Household Survey. To understand what the data tells us and the adequacy of the data is particularly important in the current Scottish Government context as the SHS is being reviewed and its purpose reconsidered. The current contract for the SHS ends in 2011 and the full survey is being reviewed and reorganised around the NPF. This means that current questions on culture, which forms a small part of the NPF, would have to be revised and essential data prioritised.

The current key policy documents from the Scottish Government include Culture Delivers (2008c), which is a publication which sought to illustrate briefly the kinds of impacts culture and creativity could have across many different policy/delivery settings. Following this is the draft Community Planning Toolkit for Culture (2009a), 
which exists to help Cultural Planning Partnerships within Local Authorities to realise the full potential of culture in their local area in delivering outcomes across a wide range of priorities. The cross-cutting potential of culture is very much emphasised in People and Culture in Scotland:

"Arts and Culture are areas that cut across many other Ministerial portfolio areas and contribute to many aspects of life in general. Participation in arts and culture has been shown to contribute to individual well-being, self-esteem, confidence, new skills, improved mental and physical health and better educational attainment. At a community level, cultural participation can contribute to community cohesion, pride and confidence, reduce social exclusion, enhance a 'sense of place', renew interest in heritage and the environment, and make communities feel safer and stronger. Culture is also related to our sense of national identity and plays an important role in attracting tourists to Scotland to enjoy our cultural facilities, heritage and landscape" (Scottish Government, 2009b, p.6).

There are also two quality frameworks available for cultural services. The current quality framework from the Scottish Arts Council (2009) focuses on quality, public engagement, artistic leadership and government. The first draft Quality Improvement Framework for Culture and Sport, 'How Good Is Our Culture and Sport' (Scottish Government, 2009f), is also being trialled. It aims to help local authorities and others to self-evaluate the quality, impact and inclusiveness of their provision, and to plan for continuous improvement.

These documents provide a general overview of how culture can potentially contribute to all of the National Outcomes in different ways. Their main audience is local authorities throughout Scotland. Cultural activities and services are placed as potential contributors to the Scottish Government's overall Purpose by integrating into all its aims and outcomes. We have already seen that the overall data within the SHS can offer significant links to many higher-level sectors such as health, education and occupation. Importantly, however, the Scottish Government strategy places cultural provision and policy creation at local authority level. The Concordat agreement encourages local authorities to create their own local indicators around culture. In this local policy context the SHS provides limited information. 
The importance of being able to provide viable local area information is important for the Scottish Government's outcomes based approach. Through the Single Outcome Agreements, local authorities are asked to create and measure local indicators and show how they fulfil the overall National Performance Framework. There is a limited amount of cases generated by the Culture and Sport Module, which creates a challenge to gather local level, in-depth information on culture. The Module was never really designed to do this, showing methodological difficulties in the new policy context. Difficulties in gathering local information are further highlighted below. It shows, for example, that those living in other urban areas or small accessible towns are least likely to participate. This suggests that the SHS is unable to give some local authorities the information they need to show their contribution to the local agenda. It also leaves them unable to access information on people in their area, who are most likely to be unable to participate (this is explored in more detail below). Offering information to help show how local authorities are fulfilling a National Framework is a challenge in its current form. To achieve a full picture at local level more linkage is needed with local measures.

\section{The Culture and Sport Module Survey Data}

The SHS main survey data contains generalised measures of cultural participation. The information provided in the Culture and Sport Module (Scottish Government, 2009 b) provides more detailed data in the topic areas of: participating in cultural activities, attending cultural events, archives and records offices, visiting a library, historic or archaeological sites, museums and galleries, childhood encouragement and early cultural exposure, internet use of cultural websites and volunteering (again for more detail on sampling see note 1). The two areas of enquiry on participation in cultural activities and attending cultural events contain further questions following this format: 
Figure 5:

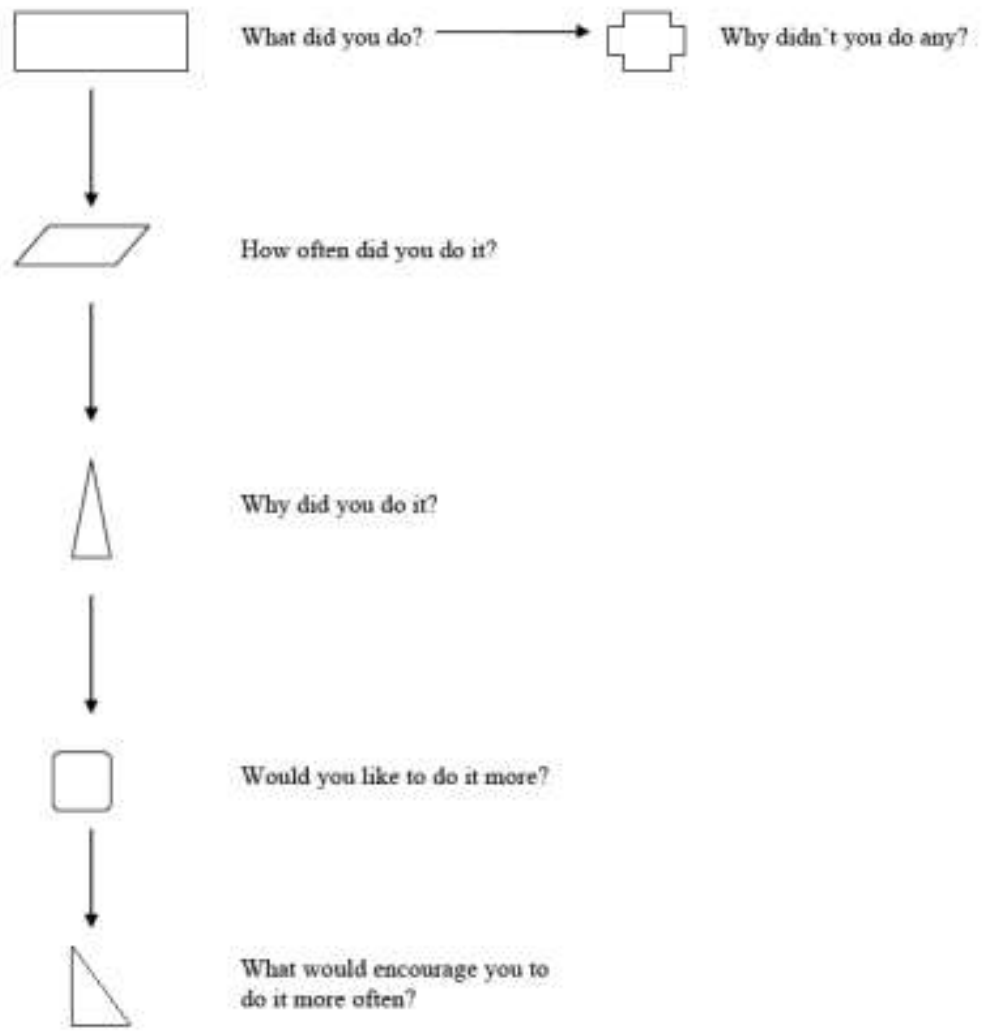

Source: (Scottish Government, 2009b, p.138)

A greater range of activities and attendance types are recorded than in the main survey and for the majority of these the questions listed above are asked of every activity. This provides a very detailed account of some minority activities and attitudes towards these by participants in Scotland. Further general figures have been released in the Module report with activities categorised in the following manner (figure 6 demonstrates the clear association between highest qualification and participation in cultural activities). 
Figure 6: Participation in cultural activities, by highest qualification

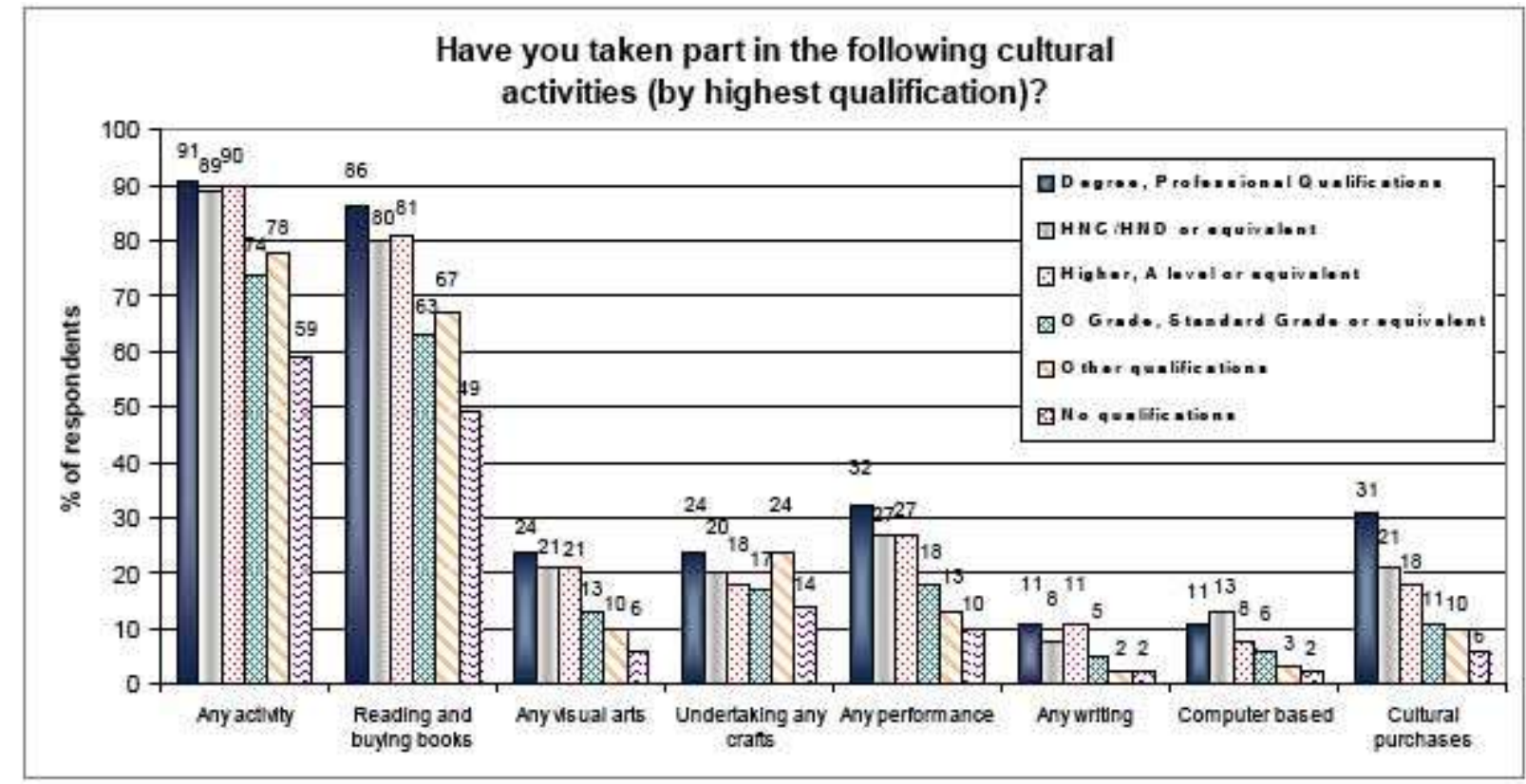

Base: All respondents (6,643), adult population 2007/2008 data

(Source: Scottish Government, 2009b, p.14, Chart 2.5)

Figure 7 also demonstrates the wide range of activity type recorded within the SHS Module:

Figure 7: Participation in specific cultural activities

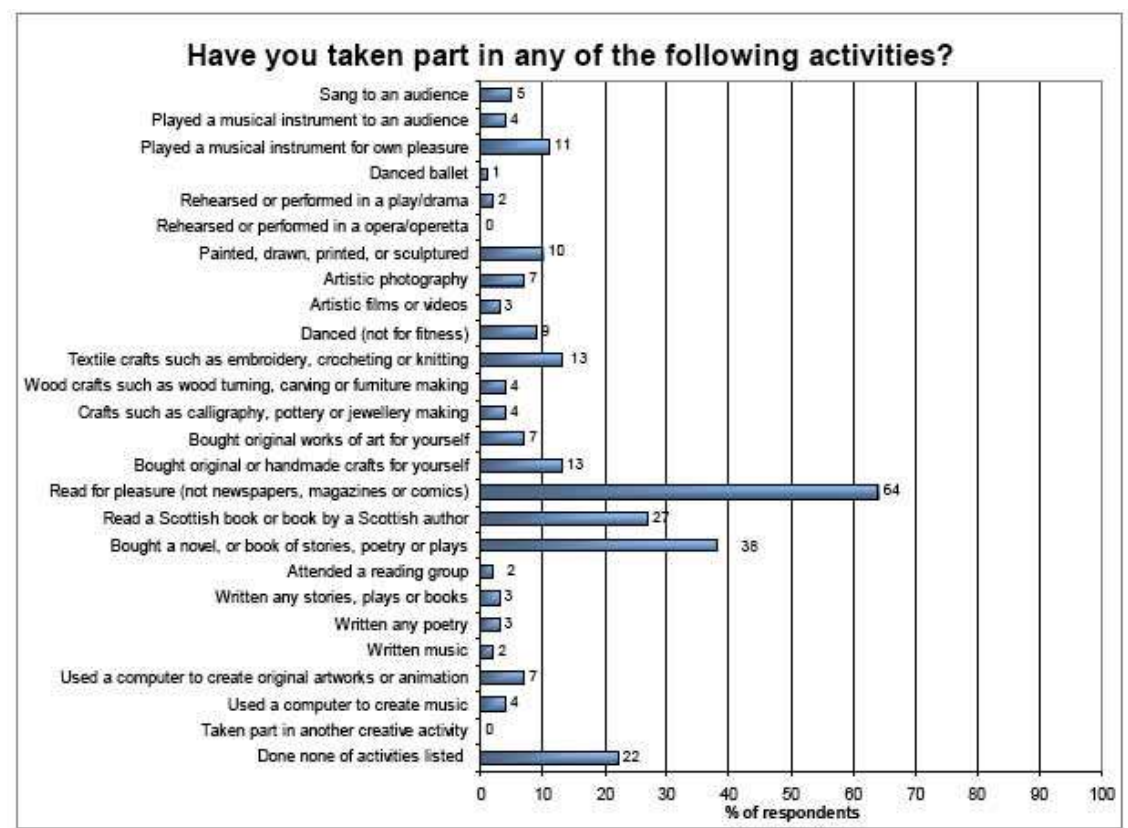

Base: All respondents (6,765), adult population 2007/2008 data

(Source: Scottish Government, 2009b, p.15, Chart 2.6) 
The Culture and Sport module contains detailed information about the socioeconomic characteristics of individuals and their participation and frequency of participation in cultural. However, this could be improved by careful consideration of the questions asked with regard to reasons for participation or non-participation. Some of these are not sufficiently specific and are therefore not particularly helpful for analysis. For example in figure 8, enjoyment is the most popular reason supplied for participation and the majority of respondents who did not participate in an activity gave the reason for not doing so as lack of interest. Whilst this is an important reason for participation that must be recorded, this does not necessarily assist in the identification of what was or was not enjoyable about the activity. These simplistic response categories potentially offer the policy maker the least potential leverage in policy responses. It is also possible that people may give similar reasons for participating in an activity but these can be due to quite heterogeneous factors.

Figure 8: Reasons for participating in cultural activity

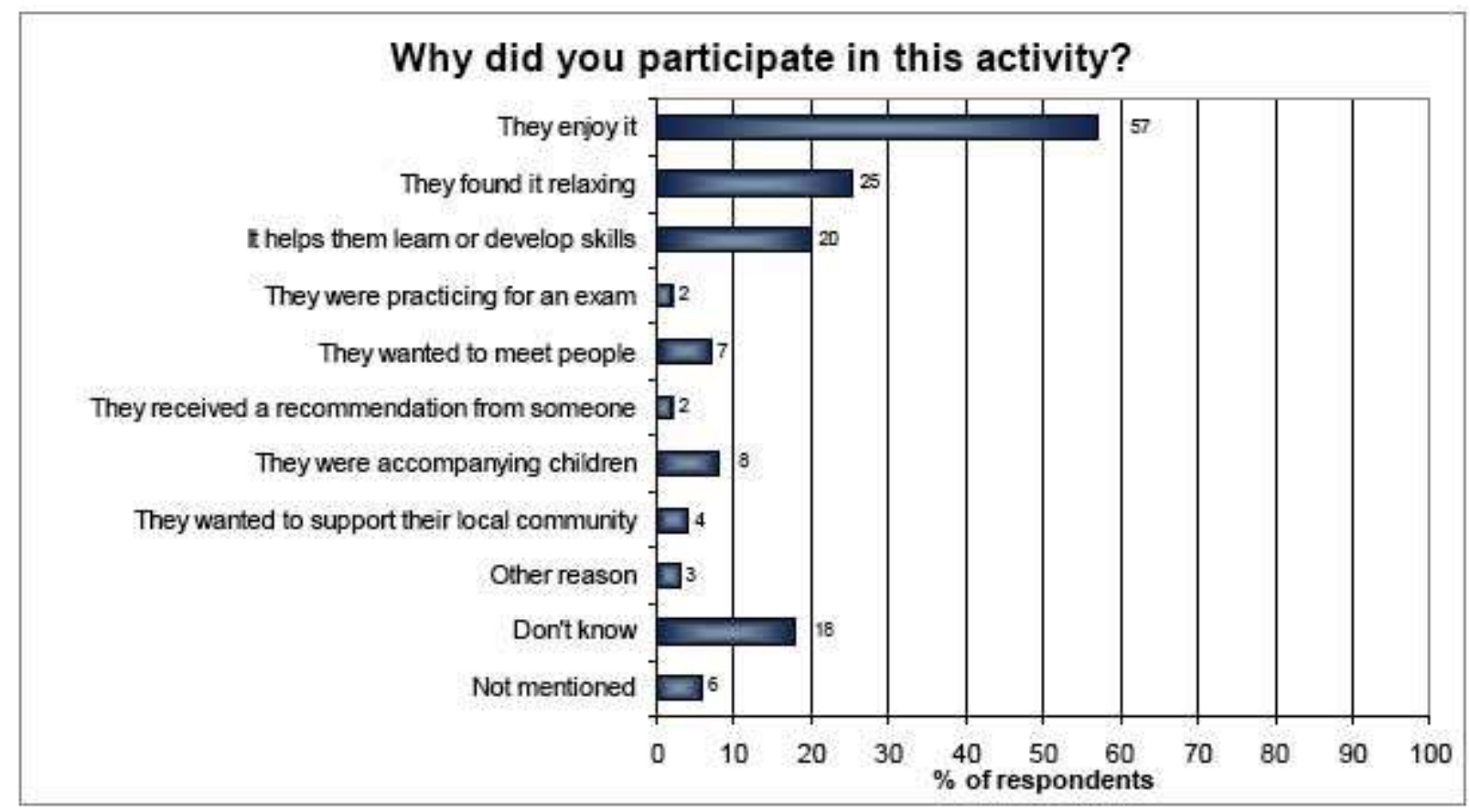

Base: Respondents who had taken part in a cultural activity in the previous 12 months (1,993), (Source: Scottish Government, 2009b, p.24, Chart 2.15)

The variables regarding more specific areas of culture (e.g. Museums and Galleries onwards) are somewhat clearer. The inclusion of the response "to see something to interest children" as a reason for attending Museums and Galleries is an example of a 
well thought-through response, as this has anticipated a potential reason which also concurs with something that a policy maker might be able to influence. As a consequence of this, this response links well with the section of the report and the variables devoted to childhood encouragement and early cultural exposure. Whilst there may be some issues regarding recall, there are clear patterns of association between childhood exposure to cultural activities and attendance and socio-economic characteristics. However, there are still difficulties in linking these to individual local authorities.

\section{Local Authority Level Data in the Culture and Sport Module}

Local Authority level information is published in the form of tables and charts available on the Scottish Government website ${ }^{5}$. This information is provided at local authority level by socio-economic variables. For the cultural information however, there is the issue of sparseness. Cell counts below 100 are not published for reasons of disclosure and potential identification of participants. Even if such data were to be published, the small size of the sub-samples would mean that confidence intervals around estimates would be large (i.e. a large degree of imprecision due to the increased probability of sampling error around estimates based upon small sample sizes). A means of working around this issue is to identify information at different levels and generalise based upon these findings. This can be summarised as follows:

- Identify differences in the cultural indicators by local authority using the main survey data;

- Identify general differences in the outcome measures by socio-economic characteristics using the main survey data;

- Identify differences in the socio-economic characteristics of local authorities using the main survey data.

This can then be referred to further information providing reasons (for Scotland as a whole) for or against participation, using evidence from the Module. This is a plausible solution but it is imprecise at the local authority level. It is possible to fit

\footnotetext{
${ }^{5}$ see http://www.scotland.gov.uk/Topics/Statistics/16002/LATablesAnnual2007-2008
} 
some multivariate models to the SHS local authority data if these summarise the differences in participation between local authorities. For example, Widdop and Cutts (2011) provide a multilevel latent class analysis of cultural attendance and participation (including differences between and within local authorities) using the SHS Culture and Sport Module, which establishes there is variation in attendance and participation between local authorities controlling for the socio-economic characteristics of respondents living within these local authorities. However, this cannot provide further definition around the attendance and participation in particular local authorities beyond the general level of overall attendance or participation. As a consequence, the conclusions reached using this information tend to be based on the most likely associations between cultural participation and prevalence of people with socio-economic characteristics that match these within the local authority. It is difficult to avoid this issue as the solution is a larger sample size. Within the context of the SHS this is probably prohibitive in the present economic climate. It is better perhaps to concentrate analyses at the Scottish level instead. This is problematic as the second aim of the SHS is: "To permit disaggregation of information both geographically and in terms of population sub-groups (such as families with children or the elderly)" (Scottish Government, 2009a, p.2). With regard to local authority area information, the SHS is unable to fulfil these aims and objectives of offering geographically disaggregated information.

It is debateable whether national household surveys are suitable as a source of local authority information by local authority but there appears to be little alternative. In England, work has been conducted by the DCMS via telephone interviews to investigate cultural participation by local authority. However, most estimation continues to use household surveys. In the policy context that was outlined above this is a particular issue. Local authorities, through the SOA's, set out local indicators for culture. These can be wide or specific to local areas. In both cases the SHS will be unable to offer any measurement or evaluation as to the success of these policy outcomes and indicators. 


\section{Lack of data on non-participants}

The previous section also demonstrates the lack of information available on nonparticipants. This is another challenge within the policy context, which has consistently asked cultural services to target non-attendees as part of their policy strategies. As figure 7 shows, only those who have indicated they participate are given more detailed questions. This is very surprising, as since 1999, there has been a focus on hard to reach groups through social inclusion policy in Scotland. With the aim of "maximising the social benefit of culture", New Labour promoted "community-based cultural and sporting activities in the context of Social Inclusion Partnerships, to include a wide range of activities" (Scottish Executive, 2000, p.11). The context of engaging hard to reach groups through culture is still highlighted in Scottish Government policy where "all those involved in provision of culture are encouraged specifically to target non-attenders, and to consult them, when planning, developing, appraising and marketing their cultural 'product', whether it be an exhibition in a museum or gallery, a music or theatre event, or a library service" (Scottish Government, 2008, p.10). This is within the national outcome of creating an 'inclusive Scotland'. Despite this strong policy focus on non-attendees, the SHS has never targeted them for more detailed questions around their motivations or barriers to participating. To adequately fulfil these policy expectations, new questions would need to be placed in the SHS that specifically explore non-participants. Without these, local authorities and cultural services would find it difficult to gain in-depth knowledge on non-participants. Demonstrating how they are fulfilling this particular Scottish Government outcome is a difficult challenge.

\section{Comparing other Surveys}

It is clear that the SHS is a rich source of information about cultural participation in Scotland, especially regarding those who have participated in or attended a cultural activity in the last 12 months. However, local authority data is less well provided in the Culture and Sport Module and data on non-participants is lacking. This section explores other surveys to see if they have solutions to these challenges. In order to identify the suitability of other surveys and to learn from them, three criteria have been used. Firstly, whether the data in the survey in question is contemporary? 
Secondly, whether the data is appropriate (i.e. valid and representative) for Scotland? Thirdly, whether the data examines the adult population? It is also necessary to compare the survey design and content. The ESDS Data Archive is a major source of information on available survey data resources. The term "culture" can be misleading with many surveys containing aspects of culture that relate to:
a) National identity (cultural identity)
b) Civic (cultural) engagement \& volunteering
c) Ethnicity (cultural background)
d) Employment in cultural industries

The potential contribution of the SHS to policy in this sector is significant as it covers a larger population than comparable studies in Scotland, such as that conducted by the Scottish Arts Council (now Creative Scotland) ${ }^{6}$. The Scottish Arts Council began surveys in 1991 with the latest survey figures available being 2008. The latest survey found that $77 \%$ of adults had taken part in a cultural activity and generally found a higher percentage of participation and attendance than the SHS (SAC, 2008). In a review of the Scottish Taking Part survey, Hibberd (2009) notes issues with its questions and remit, noting limits to the value of its contribution. Hurley et al. (2008) also noted a variety of issues with the SHS when comparing it with other surveys that look at cultural activities. For example, differences in volunteering numbers in Scotland and England were attributed to definitional and formatting issues as well as the structure of questions within the survey itself. A review was commissioned due to the SHS consistently showing lower numbers when compared to other surveys in both Scotland and Wales (an example being the $72 \%$ and $77 \%$ figures for the same year above).

This inconsistency has already been noted in the cultural sector, with Madden (2005, p.299) observing that there is a general 'sloppiness' in statistical comparisons. Furthermore, there have been questions raised regarding overall quality of data generated in the cultural sector and whether it has ever been used constructively in regards to policy (Selwood, 2002a, 2002b, 2006). Thus, although the SHS is a rich

${ }^{6}$ Creative Scotland began in 2010 and is a combination of the Scottish Arts Council and Scottish Screen. The Scottish Arts Council Survey (SAC 2008) conducted 4,944 face-to-face in-home interviews between March and June 2008. 
source of statistical information there are questions regarding its comparability to other surveys and the overall quality of the data it generates. Furthermore, the relationship between data and its impact on policy making within the cultural sector is much more complicated than the overall lack of evidence.

Other surveys can be compared with the SHS in the UK. These can highlight any potential improvements to the SHS as it currently stands. The culture Module was firstly designed to be compatible with the Taking Part surveys in England (Aust \& Vine 2007; DCMS, 2010). Cultural sector trends in participation, attendance and attitudes have been generated from 2005. The Taking Part surveys have been reviewed as the best in the UK cultural sector for clarity and analysis (Davies, 2007). Arts Council of Wales (2010) has also released their findings from their 2010 survey on attendance and participation. Other sources have also been analysed such as the Cultural Capital and Social Exclusion (CCSE) project and the Arts Council of England's 2001 attendance, participation and attitudes survey (Gayo-Cal, 2006). Also the TGI (Target Group Index) has generated arts attendance information since the 1980s (for more details see Keaney, 2008, who also discusses key qualitative sources). What is clear, however, is that there is less of academic analysis of Scottish and Welsh survey results as there has been for England.

\section{Scotland}

The most recently available data from the Taking Part in Scotland survey series (commissioned by Creative Scotland, formerly the Scottish Arts Council) is from 2008. Creative Scotland (at the time the Scottish Arts Council) produced a series of reports via the biennial Taking Part in Scotland survey. This data has provided valuable information collected in 2004, 2006 and most recently 2008 (with prior surveys of a different format collected by the SAC in 1991. 1994, 1998 and 2001). However, it has generally had a smaller sample that the one offered in the SHS and the Culture and Sport Module, with 2,110 being the core sample representative of Scotland as whole (quota sampling was used within geographical areas). The most recent of these in 2008 contained data from 4944 face-to-face interviews. The specific objectives of the 2008 study were as follows: 
- To collect data robust enough to allow for the identification of any statistically significant change in the overall levels of attendance and participation amongst the adult (aged 16+) population in Scotland.

- To collect robust data amongst a number of under-represented groups, namely - minority ethnic communities, residents of deprived areas, disabled people, women, residents of rural areas, people aged 16 to 24 , people aged $65+2$.

- To explore and examine as far as possible, any variations and trends between the 2004, 2006 and 2008 data from the perspective of the population of Scotland as a whole, for the key under-represented groups as well as any regional differences (Scottish Arts Council, 2008a, p.8).

This forms a useful comparison dataset with the Scottish Household Survey. However, the surveys cannot be directly compared due to the different research methods used in each, with the SHS main survey and Module meeting national statistics requirements by using a sampling method of random representative sampling, whilst the SAC survey uses a quota sampling survey method, which does not meet the criteria of national statistics. The SAC survey does however provide a useful pattern of 'trends' since 2004, which the main SHS and Module has not yet been able to do.

To help improve the data generated, a particularly strong series of questions include likert scales asking the respondents the extent to which they agree or disagree with statements that include more practical or instrumental questions about cultural participation and attendance. For example, "I would attend more arts and cultural performances if they took place closer to where I live." Whilst these are potential reasons for non-attendance within the SHS Culture and Sport Module by presenting these as a list of reasons, rather than as a likert scale, there is a tendency for respondents to give a single simple response. The manner in which the question is asked in Taking Part in Scotland enables analysts to better understand the relative importance of these factors. This gives an example of how questions could be more effective and helpful to policy makers. 
Questions like the one above also give more insight in how to attract non-participants. Useful questions including in the Scottish Taking Part Survey were (to all respondents): "Which events/activities would you consider attending in the future? What is the maximum distance willing to travel to attend/participate? and which factors would influence your choice of event/activities?" The latter of these two questions is particularly useful as it gives the respondent the choice of largely instrumental answers (such as recommendations, advertisements and experiences). This is more useful to policy makers and particularly showing ways to contribute to the Scottish Governments economic agenda. Thus the Taking Part survey conducted by Creative Scotland (the Scottish Arts Council) does help provide questions that could easily be applied to non-participants. This could give useful insight for cultural services and local authorities as they try to attract and cater for hard to reach groups.

\section{England}

There are more large scale data sources available in England. Keaney (2008) describes available data sources in England, in particular the Taking Part survey but also the Target Group Index (TGI), a consumer survey of 25,000 adults. The principle advantage of Taking Part as a survey is the public availability and range of socioeconomic measures collected in conjunction with the cultural indicators (enabling more thorough analysis). Keaney (2008) also comments on the weakness of overly general response categories (such as "liking going to these events") which do not help us understand motivators in a sufficient level of detail.

Taking Part in England (Department for Media Culture and Sport, 2010) has a complex stratified sampling design detailed in the technical report (see TNS-BMRB, 2010). The sampling frame was the residential postal address file and then sampled by primary sampling units based upon population density. Some aspects of the survey are very similar to SHS format with questions that include: 
- In the last 12 months, have you done any of these activities?

- Did you do this: in own time, for paid work, for academic study, part of voluntary work, or for some other reason?

- How often did you do this (in the same format as for the SHS)?

It is also asked within the last 12 months how many times someone has participated in an activity, not just how often. There are further questions about levers of participation and attendance including scale measures how much the participant enjoyed the activity, how likely they are to do it again, whether they would recommend the activity to a friend or family member. The dissemination of data and general awareness of existing resources is equally important to data collection. Both Taking Part surveys in England and Scotland have recently seen greater efforts to improve this in terms of promotional work, uploading of the more recent survey information to the ESDS and development of web tools to aid interaction with the data. Recently the Scottish Government has been seeking to follow these recommendations but potential improvements could still be made to the questions asked and data dissemination in the SHS.

For further interest, other activities include Gayo-Cal (2006) who compares the Cultural Capital and Social Exclusion (CCSE) Survey with the Arts Council Survey (2001) in England and Wales (Skelton et al., 2002). The analysis includes forms of leisure activity not recorded in the SHS, such as pub going, bingo and night clubs. Taking Part includes these activities in a 'Free Time' question (Department for Media Culture and Sport, 2010). Whether such activities are considered 'culture' or 'low culture' (for further consideration see Bourdieu and Passeron, 1990) or whether the Scottish Government might wish to measure these with reference to policy is debatable. However, to ignore them is to exclude part of the potential understanding of what people who do not participate in 'culture', do with their time instead. GayoCal's (2006) paper is also instructive as it demonstrates a more advanced statistical analysis. This could be replicated with the large sample size of the SHS were it not for the lack of "low culture" outcome variables mentioned. This is relevant to policy makers as there are few multivariate analyses of cultural participation. 
Another major resource which has cultural indicators that could be helpful to the SHS is Growing Up in Scotland (Scottish Centre for Social Research, 2010). This is a longitudinal and cross sectional study of children in Scotland started in 2005/2006. 8,000 children were initially involved (including 5,000 babies and 3,000 toddlers) selected from a sampling frame of child benefit records. The sample was stratified by randomly selected datazones (small geographical areas) based on region and deprivation. It is a birth cohort study with the principal areas of interest being childcare, education, social work, health and social inclusion. There is a small aspect devoted to questions about cultural exposure as a child which may be of relevance. The parent of the child is asked whether the child has been to: the library (not including the school library); a live performance such as a musical concert, play or pantomime; a swimming pool; an art gallery, museum or historical site; a zoo, aquarium or farm (not including cases where the child lives on a farm); the cinema; athletic or sporting event in which s/he was not a player; a religious service or event; or none of these. The parents are then asked for each of the listed categories, how often in the last 12 months they had been and who the child went with. These questions are quite simple but might be useful in the future for identifying childhood exposure to the arts as the survey develops.

The Growing Up in Scotland survey is very similar to The Millennium Cohort Study (Hansen et al., 2010). This is a UK wide longitudinal study of 14,000 children born between 2000 and 2002. Data are currently available for the first 7 years of life collected at 4 points. The GUS and MCS are similar in design being selected from childhood benefit records with over-representation of disadvantaged areas to ensure statistical significance. The questions are similar to those in the GUS. Firstly, "which out of these has the child been to in the last 12 months? A play, pantomime, music concert, circus or other live show, Art gallery, museum or historical site, Zoo, aquarium, wildlife reserve or farm, Theme park or funfair, Cinema, Professional sporting event as a spectator or none of these? And secondly, how often has the child been to a library (non school library) in the last year?" For both GUS and the MCS, these are both useful sources of supplementary information but not the basis for 
understanding cultural participation currently. They firstly refer to children in the survey and there is insufficient detail.

In conclusion to this section, the comparison of alternative surveys containing cultural information in Scotland (and other UK countries) has demonstrated that improvements can be made to the questions within the SHS. This is particularly important with respect to the policy objectives of the measurement of Scotland in culture. Exploring different questions on culture throughout the UK has also shown the various understandings of culture, participation and cultural activity.

\section{The Varied Definitions of Culture}

It is important to note here that there are issues in defining culture. Problems are also linked to what counts as a cultural activity. Williams (1979, p. 87) shows that 'culture' is one of the most complicated words in the English language and is used in different disciplines for incompatible trains of thought. He shows it can now stands for intellectual, spiritual, aesthetic development, a particular way of life or working practices and work for creative activity. Also, the definitional debates around culture have always circled around the idea of 'high' and 'low' culture. They are influenced by educational achievement, occupation, family background and of course social class (Bourdieu, 1984). Positions and relationships within the cultural field are dominant or subordinate by virtue of access to different types of capital which are at stake in the field (Bourdieu, in Jenkins, 1992). Griswold (2008) in particular outlines the distinction between 'high', 'elitist' culture and 'low', 'mass' culture. The former refers to serious literature, the performing arts, art galleries, museums that are viewed as fragile, sacred, in need of preserving. The other is linked to mass production for 'others' and often linked to the market and profit making, attributing it with less importance than 'art for art's sake', which 'high' culture aims to embody. 'Popular' culture is another, but more optimistic, form of 'mass' culture representing the nonelite majority (Griswold, 2008). Cinema attendance could be classed as 'pop' or 'low' cultural activity - this raises the question of whether the high number of people going to the cinema feeds into overall cultural attendance figures and thus helps justify overall funding for the 'arts'? Featherstone (1991), however, highlights that the distinction between high and low culture has diminished with the way culture has 
become integral in everyone's lives. The argument, however, still remains much contested. Although this division has been reproved and refuted for a long time, it still prevails when defining culture (Griswold 2008). Overall, when the SHS measures cultural participation and attendance, there are many activities some would not consider as a cultural activity. This distinction is more important when highlighting that reading and cinema attendance take up nearly half of participation figures. For example, reading - the main cultural activity recorded in the SHS - is only one small part of the current definition of the arts offered by the Scottish Government, which includes:

"Performing arts (music, drama, dance, opera), the visual arts (painting and drawing, photography, sculpture, architecture, design,), literature (creative writing, storytelling, reading), community, ethnically-oriented and traditional arts (including Gaelic arts), festivals, a wide range of craft activity, and multimedia arts (TV, radio, film, moving image artforms, designer fashion, and computer games/interactive leisure software)” (Scottish Government Cultural Toolkit, 2009, p. 3).

The surveys explored above report a further range of activities which demonstrates that there are a range of topics and surveys that are considered under the heading of culture. This offers an effective look at how questions in the SHS could be improved. The SHS, however, is already quite effective for what it does and no other sources solve the problem of measuring local indicators. Looking at these surveys it is not clear if there is comparable data that would help local authorities show they are fulfilling the National Performance Framework. This then leads us to question the type of method within the outcomes based policy context and the ability of surveys as a method to answer those types of questions.

\section{The Scottish Household Survey as a Policy Tool for Cultural Activity}

The above sections have shown the uses and the challenges that relate to using the SHS to inform current Scottish policy. However, the cultural sector has always been set in a context of disconnection from policy (Bennett \& Mercer, 1998). This may be because there are concerns around definitions, clarity and methodology regarding the evidence base on the impact of the arts (Belfiore \& Bennett, 2007). McCall (2010) 
suggests that cultural policy makers, including MSP's and civil servants in Scotland, advocate the instrumentalist value of culture but place it as a low policy priority. Gray (2006) also shows that there are several challenges for the cultural sector including:

- The absence of a clearly defined arena of action;

- A lack of political significance for the cultural policy sector;

- The fragmented organisational universe that it operates within;

- A variation in geographical scale that it operates within;

- The effectively reactive, rather than proactive, nature of the policy development that it involves.

The increasingly instrumental view of current cultural policy has been noted in both a UK and Scottish context (Gray, 2007; McCall, 2010). Gray (2007) calls this a process of policy 'attachment' within the cultural sector. This is where cultural services are employed to fulfil outcomes that are not 'traditionally' cultural in nature (such as creating a healthier Scotland). In an outcomes based policy approach the instrumentalist view of policy is more prominent, as delivery is set around expected changes and actions under one overall economic purpose (so everything is a tool to work to this purpose). For the cultural sector, this is even more prominent due to the omission of specific higher-level cultural outcomes.

Despite the issues in the sector, there are a significant amount of studies building up an evidence base for the arts. For some summaries, Ruiz (2004) and Galloway (2008) offer literature reviews around the impact of culture and the arts on society. Galloway (2008) gives examples within the context of the Scottish Government's Strategic Objectives with evidence structured under healthier, safer and stronger, smarter and greener. She identified that since 2005 the evidence within the three areas of health, education and employment have developed and relates directly to the Scottish Government's Strategic Objectives. Further evidence is held of the CPPR "Impact" database in Scotland and now the new CASE (2010) database ${ }^{7}$, both of which hold

\footnotetext{
7 The contract for the "Impact" database held by CCPR will end March 2011. The Scottish Government shall hold the database in its current form while it is maintained by the DCMS. The "Impact" database shall then be integrated into the larger CASE database, http://www.culture.gov.uk/what we do/research and statistics/5698.aspx.
} 
evidence and reviews around the role and impact of culture. Thus there is an evidence base to show culture can be significant within the NPF.

The SHS provides viable and valuable national data on cultural participation and attendance. This paper has shown, however, that the SHS has challenges in being an adequate tool for helping local authorities, civil servants and cultural services in helping to illustrate how they are fulfilling Scottish policy objectives. To summarise the key points around the SHS:

- There is a lot of detailed information about cultural participation both in the main part and in the Module;

- Reading tends to inflate the headline figures for overall participation. This is shown when those reading figures are taken from the main report;

- The associations between participation and key socio-economic variables are stronger when reading is excluded;

- It is problematic to use the Local Authority information within the main section with analysis by socio-economic variables as the number of cases is too few to be reported in many instances;

- It is possible to compare general patterns of associations with local patterns of socio-economic distributions, but this is an imprecise method. However, the cost of increasing the sample size to overcome this problem would be potentially very large;

- The Module has good detail but needs questions which provide more detail about non-participants and potential levers for encouragement;

- The data curation and metadata could be improved.

Overall, there are general difficulties measuring 'culture' but the SHS provides adequate national data for Scotland on cultural participation and attendance. However, a challenge is posed when regarding the policy context. The SHS cannot provide local level information on the topical level used in the cultural and sport Module. It also provides limited data on non-participants. This creates complications in providing local authorities with specific evidence to help them show how they are 
fulfilling the NPF. Other surveys have shown minor improvements in the wording of questions but ultimately none of these sources help provide information at a local level. A more creative solution and reference to local contexts is needed.

\section{Conclusion}

Overall, the SHS and the Culture and Sport Module provide useful general information for cultural participation and attendance. The SHS, however, has serious challenges as it existed before the current Scottish Governments economic agenda. An outcomes-focused approach is a new strategy for Scottish policy and needs general development for frameworks that allow for measurement. The SHS cannot give full information on how culture can fulfil the National Performance Framework. This is not to say its value is diminished for generating cultural statistics. The SHS is the key survey to do this. It is important to remember that it is a survey data resource and not an audit tool for measuring service use. The survey could be improved to assist in this capacity without spoiling the continuity of previously collected measures.

To make it more relevant, further questions for non-participants (a notoriously hard group to generate data for) could be adopted. Better questions would include improved levers and motivators for participation/non-participation and attendance/non-attendance. These could be included alongside existing measures for comparison with previous years of SHS data to ensure continuity. As a simple step, much could be learned by harmonising some new measures with Creative Scotland's Taking Part Surveys. This would benefit the SHS and Taking Part surveys. This would ensure consistency with existing surveys and generate information on a key Scottish Government concern.

To measure the NPF over time, longitudinal data is the only way to measure and track change. With all cross-sectional data, the identification and isolation of particular events (with the context of age, period or cohort effects) are not verifiable with crosssectional data. Longitudinal data can always be used cross-sectionally but not vice versa. This is relevant in order "to allow early detection of national trends" (Scottish Government, 2009a, p. 2). Longitudinal data can satisfy this aim and would be a 
valuable resource. It is planned that the Taking Part in England surveys will collect longitudinal data using a repeat interview design from 2011-2014 and the equivalent collection in Scotland would be beneficial. However, the collection of this would incur expense and changes to the manner in which the data is collected, which might not aid comparability between previously collected SHS data. It is important to note that there may not be a case for another longitudinal resource for Scotland (given the existence of the Millennium Cohort Study, Growing up in Scotland and the UK-HLS) but it is worthy of consideration within a wider Scottish data strategy (see Gayle, Playford and Lambert 2008). It is recognised that it may not be necessary to fulfil the goals described in the NPF.

The issue with local authority data is not as easily tackled. Due to the costs of increasing sample sizes to allow for robust local information, we suggest a different methodology could be taken with local authority data. Furthermore the provision of culture within the UK is an eclectic mix between private, public, local, community and voluntary sectors. Local authorities themselves have been collecting information on cultural participation. A more cooperative approach between local and central governments and other bodies may be key in identifying the best approach.

The policy context in which the SHS has been embedded since 2007 proposes certain challenges. Importantly, it was not designed to provide evidence for an outcomes based approach. The National Outcomes of the Scottish Government are ambitious and need different measurements to track them than exist in the SHS. This is one of the main motivations for the review of all the Scottish Government surveys. An outcomes based approach that looks to measure changes in such things as 'Scotland's reputation' is difficult. It must be remembered the policy approach is relatively new and needs much more development on its evaluation. It is assumed that economic growth results in fulfilling the strategic objectives, which are fulfilled by the National Outcomes, which in turn are fulfilled by the national indicators. This creates a rational process where $a$ leads to $b$ leads to $c$. Furthermore, actions are motivated by more than simple rational choice and this theoretical approach ignores important shaping features such as social norms, structures and collective action (Scott, 2000). Sutton (1999, p.5) points out that a 'linear model' of policy-making, characterised by objective analysis of options and separation of policy from implementation, is 
inadequate. Instead, policy and policy implementation are best understood as a 'chaos of purposes and accidents'. What this means for the SHS is that it simply cannot give a viable idea of policy implementation at ground level. More creative solutions are needed to generate evidence of policy delivery and implementation in Scotland.

The SHS may also be a valid method to monitor future potential changes in cultural participation and activity in Scotland. Both the Commonwealth Games, being hosted in Glasgow in 2012, and the UK wide Cultural Olympiad (a four-year programme of cultural activity) may affect cultural participation and attendance figures significantly. On the other hand, local authority plans to vastly cut cultural provision may also have an effect. There have already been cuts throughout Scotland, with the Highlands being hit the hardest (McCracken and Millar, 2011). Some local authorities are potentially planning to cut their arts budgets by completely (McCracken, 2010). In the absence of longitudinal data, the SHS is best placed to monitor participation and also investigate the causal links and impacts of future changes.

Overall, the SHS is an excellent data resource and as it is reviewed, care must be taken to not lose or limit the data. The loss of questions observed over time is detrimental to the process of measuring cultural participation in Scotland. However, new approaches need to be found that are more in tune with the current outcomes focused agenda of the Scottish Government. Most importantly, local authorities need to be able to access or generate information that links them to the National Performance Framework to allow them to help justify cultural provision. In today's climate of cuts, this is an even more important argument for cultural services to be able to make. Steps could be taken to ask better questions and focus on nonparticipants. Also, a more integrated approach with local government would be the best way forward. Linking up local and central government along with other cultural bodies' information would be a step in the right direction to generating a full picture of cultural provision and participation within Scotland. 


\section{Notes}

1. There are four principle questions in the SHS main section regarding cultural participation, attendance at cultural events and the frequency of both in the last 12 months. For each of these 4 questions there are then a list of activities and events (for full details see Scottish Government 2009a). Seventy questions on the topic were asked in the SHS Culture and Sport module (Scottish Government 2009b). Thus the main section of the SHS can offer better representative data with more cases, while the Module offers better topical detail. The analysis of the main section of random adult interviews was based upon 24,615 interviews conducted over 2007/2008. In practice, respondents providing data for cultural analysis was 19,532. In the Module, the number of similar respondents was 6,763. The SHS is a multi-stage stratified sample starting with disproportionate stratification by local authority to ensure the sample size is sufficiently large within local authorities to permit analysis at this level. Within mostly urban local authorities, sampling is un-clustered. In rural areas, sampling is clustered due to the cost in interviewing over large distances. Within households interviewed, a random adult is selected (see Scottish Government, 2009a). The random adult data used in this paper is weighted to correct for disproportionate selection by local authority and difference in probability of selection within household. The addresses selected are further randomly assigned into subsamples or 'streams' numbered 1-10. For 8 of these streams only the main survey questions (i.e. without Culture and Sport questions) are asked. The remaining 2 streams are asked both the main set of questions and those contained within the Culture and Sport Module.

2. National Statistics Socio-Economic Classification (NS-SEC) is recorded in the SHS but unfortunately the proportion of missing data is high (nearly half, 10,692 random adults responded to this question). The figures are therefore reported (see figure 6) but SIMD is anticipated to be a better indicator of material circumstances (in the SHS). This is unfortunate as occupational information provides a good indication of lifestyle, potential working conditions and affluence. SIMD is a complex variable constructed using multiple indicators at multiple-levels. The association remains similar to SIMD but with a marked difference between managerial, professional and intermediate occupations and other occupational groups, which is of potential interest to researchers (especially with regard to Bourdieu's work). It must also be noted that the missing data in this measure may be differential (i.e. greater likelihood of non-response by NS-SEC category) and this may influence the outcome.

3. The Concordat agreement was made on 14 November 2007 between the Scottish Government and the Convention of Scottish Local Authorities (CoSLA). The Scottish Funding Council (2008: 1, original emphasis) sets it out as "the terms of a new relationship, whereby national government will concentrate on what has to be achieved rather than how it is to be achieved. This approach will be supported by the move away from micro-managing local government services nationally, evidenced already by the removal of ring fenced funding and separate reporting arrangements and the commitment that the Scottish Government to work with local government to streamline the regulation of services and to reduce the burden of audit and inspection through implementing the Crerar Review. Specifically, the Concordat is based on:

- $\quad$ Single Outcome Agreements (SOA);

- Reduction in ring-fenced funding;

- Streamlining bureaucracy and reporting requirements;

- Retain efficiency savings; and

- Commitment of no reform of local government structure during the term of the current Parliament

For the full agreement follow this link: http://www.scotland.gov.uk/Resource/Doc/923/0054147.pdf

4. A number of surveys contain relevant information but in a tangential form. For example, the UK Time Use Survey (2000) contained some cultural activities listed in diaries of participants. The British Social Attitudes Survey contained questions relating to aspects of national culture and attitudes to government spending on culture and the arts. The following surveys might be expected to contain information but did not have cultural questions: The British Household Panel Survey, Labour Force Survey, Northern Ireland Social Attitudes Survey and the General Household Survey. The 1946 National Birth Cohort (MRC NSHD, National Survey of Health and Development), 1958 National Child Development Survey, and the 1970 British Cohort Study are all major cohort studies and are frequently used in historic socio-demographic analyses but do not contain relevant information on culture. The General Household Survey is not a like-forlike equivalent for the SHS despite the naming convention. It is a much older survey with an emphasis on socio-economic variables and characteristics of households. 


\section{References}

Arts Council of Wales (2010) Arts in Wales Survey 2010, TNS research International, http://www.artswales.org.uk/what-we-do/research/current-research/artsinwales-2010, accessed 17/03/11

Aust, R., \& Vine, L. (Eds). (2007). Taking Part: The National Survey of Culture, Leisure and Sport. Annual report 2005/6. London: Department for Culture, Media and Sport.

Bennett, T., and Mercer, C. (1998). Improving Research and International Cooperation for Cultural Policy, The Power of Culture, Australian Key Centre for Cultural and Media Policy: UNESCO

http://www.powerofculture.nl/uk/archive/commentary/bennet.html, accessed 13/07/10

Bourdieu, P. (1984) Distinction: a Social Critique of the Judgment of Taste, trans.

Richard Nice, London: Routledge and Kegan Paul

CASE Programme (2010).

http://www.culture.gov.uk/what_we_do/research_and_statistics/5698.aspx, accessed $28 / 07 / 10$

Croxford, L., Iannelli, C. and Shapira, M. (2007). Documentation of the Youth Cohort Time-Series Datasets: ESRC Research Project on Education and Youth Transitions in England, Wales and Scotland, 1984-2002 (Study Number 5765), Centre for Educational Sociology, University of Edinburgh. See http://www.esds.ac.uk/findingData/snDescription.asp?sn=5765\#doc

Davies, S. (2007). 'Commentary 2: One Small Step Taking Part and Museums', Cultural Trends, 16(4), 361-371

Department of Culture, Media and Sport. (DCMS) (2010). Taking Part Surveys, Statistical releases, http://www.culture.gov.uk/what_we_do/research_and_statistics/7184.aspx , 26/10/10 
Featherstone, M. (1991). Consumer Culture and Postmodernism, London: Sage Publications

Galloway, S. (2008). The evidence base for arts and culture policy. A brief review of selected recent literature, Glasgow: Scottish Arts Council

Gayle, V., Playford, C. J. \& Lambert, P. S. (2008). Scottish Social Survey Data, Past, Present and Future - Does Scotland Need its Own Data Strategy? Radical Statistics, 97, 82-97.

Gayo-Cal, M. (2006). 'Leisure and Participation in Britain', Cultural Trends, 15(2/3): $175-192$

Gray, C. (2006). 'Managing the Unmanageable: The Politics of Cultural Planning', Public policy and Administration, 21(2), 101-113

Gray, C. (2007) 'Commodification and Instrumentality in Cultural Policy', International Journal of Cultural Policy, 13(2), 203-215

Griswold, W. (2008). Cultures and Societies in a Changing World, $3^{\text {rd }}$ ed, London: Pine Forge Press

Hibberd, L. (2009). 'Review of Scottish Arts Council Report, Taking Part in Scotland 2008', Cultural Trends, 18(4), 333 - 336

Hogwood, B.W., \& Gunn, L. A. (1984). Policy Analysis for the Real World. Oxford: Oxford University Press.

Improvement Service. (2009). Local Outcome Indicators, http://www.improvementservice.org.uk/local-outcome-indicators/, accessed 21/07/10

Jenkins, R. (1992) Key Sociologists: Pierre Bourdieu, London: Routledge 
Keaney, E. (2008). 'Understanding arts audiences: existing data and what it tells us', Cultural Trends, 17(2), 97-113

Madden, C (2005). 'Cross-Country Comparisons of Cultural Statistics: Issues and Good Practice', Cultural Trends, 14(4), 299-316

McCall, V. (2009). 'Social Policy and Cultural Services: A Study of Scottish Border Museums as Implementers of Social Inclusion' Social Policy and Society, 8(3), 319331

McCall, V. (2010). 'Cultural services and social policy: exploring policy makers' perceptions of culture and social inclusion', Journal of Poverty and Social Justice, 18(2), 169-183

McCracken, E. (2010) The council that wants to chop its arts budget to zero, The Scottish Herald, http://www.heraldscotland.com/news/home-news/the-council-thatwants-to-chop-its-arts-budget-to-zero-1.1071244, accessed 10/06/11

McCraken, E. and Millar, P. (2010) Revealed: How the Scottish arts faces its own Highland Clearances, http://www.heraldscotland.com/news/home-news/revealedhow-the-scottish-arts-faces-its-own-highland-clearances-1.1100198, accessed $10 / 06 / 11$

Osborne, D.E., and Gaebler, T. (1992). Reinventing government: how the entrepreneurial spirit is transforming the public sector, Reading: Addison-Wesley Publications

Orr, J. (2008) 'Instrumental or Intrinsic? Cultural policy in Scotland since devolution', Cultural Trends, 17(4): 309-316

Pressman, J., and Wildavsky, A. (1979) Implementation, Berkeley: University of California Press

Perri. (1997). Holistic government, London: Demos 
Rhodes, R.A.W. (2000). 'Governance and Public Administration' in Pierre, J. (ed.)

Debating Governance, Oxford: Oxford University Press, pp: 54-91

Ruiz, J. (2004). A Literature Review of the Evidence base for Culture, the Arts and Sport policy, Education Department and Research programme, Edinburgh Scottish Executive, Research

Sabatier, P. A. (1986) 'Top-down and bottom-up approaches to implementation research: a critical analysis and suggested synthesis', Journal of Public Policy, 6(1), $21-48$.

Scottish Budget Spending Review (2007). A National Performance Framework, Scottish Government, http://www.scotland.gov.uk/Publications/2007/11/13092240/9, $13 / 07 / 10$

Scottish Funding Council (2008) Scottish Government Concordat with Local Authorities,

http://www.sfc.ac.uk/web/FILES/CommitteepapersRKTCommittee11April2008/RKT C08_19.pdf, accessed 08/06/11

Scottish Arts Council (2008). Taking Part in Scotland 2008, Edinburgh: Scottish Arts Council

See http://www.scottisharts.org.uk/1/information/publications/1006111.aspx

Scottish Arts Council (2009). Quality Framework guidelines for arts organisations, 2nd edition, http://www.scottisharts.org.uk/1/information/publications/1004296.aspx, accessed 28/07/10

Scottish Executive. (2000). Creating our Future... Minding our Past, Scotland's National Cultural Strategy, http://www.scotland.gov.uk/Publications/2002/11/15764/13298, accessed 25/11/08 
Scottish Government. (2007). National Performance Framework www.scotland.gov.uk/Publications/2007/11/13092240/9

Scottish Government, (2007). Scottish Budget Spending Review A National Performance Framework, Scottish Government, http://www.scotland.gov.uk/Publications/2007/11/13092240/9, accessed 13/07/10

Scottish Government. Community Planning toolkit on Poverty, http://www.improvementservice.org.uk/library/download-document/127-povertyalliance-community-planning-toolkit/

Scottish Government. (2008a). Cultural attendance and participation in Scotland based on the Scottish Household Survey 2007/2008(Culture and Sport Module), http://www.culturalcommission.co.uk/Topics/Statistics/16002/PublicationCulture, accessed 26/10/10

Scottish Government. (2008b). Culture Delivers, Edinburgh: Scottish Government http://www.scotland.gov.uk/Publications/2008/12/22094149/3

Scottish Government. (2008c). Single Outcome Agreements: Guidance for Community Planning partnerships, Improvement Service: Scottish Government Scottish Government and CoSLA (2008) Concordat, http://www.scotland.gov.uk/Resource/Doc/923/0054147.pdf, accessed 06/06/11

Scottish Government. (2009a). Scotland's People Annual Report: Results from 2007/2008 Scottish Household Survey, Edinburgh: National Statistics for Scotland See http://www.scotland.gov.uk/Publications/2009/09/01114213/0

Scottish Government. (2009b). People and Culture in Scotland 2008: Results from the Scottish Household Survey Culture and Sport Module 2007/2008, Edinburgh: National Statistics for Scotland

See http://www.scotland.gov.uk/Publications/2009/11/24085939/0 
Scottish Government. (2009c). Cultural attendance and participation in Scotland based on the Scottish Household Survey 2007/2008 (Culture and Sport Module), http://www.culturalcommission.co.uk/Topics/Statistics/16002/PublicationCulture, accessed 26/10/10

Scottish Government. (2009d). Draft Community Planning Toolkit on Culture, Edinburgh: Scottish Government

http://www.scotland.gov.uk/Topics/ArtsCultureSport/arts/CulturalPolicy/workinggrou p/CPToolkit

Scottish Government. (2009e). Cultural pathfinder programme, http://www.scotland.gov.uk/Topics/ArtsCultureSport/arts/CulturalPolicy/workinggrou p/Pathfinder

Scottish Government. (2009f). How good is out culture and sport? A Quality Improvement Framework for culture and sport provision Draft, SG, VOCAL, HMIe http://scotland.gov.uk/Topics/ArtsCultureSport/arts/CulturalPolicy/workinggroup/HG $\underline{\text { IOCS }}$

Scottish Government. (2010). Summit: Culture and Creativity: a Partnership Approach, Scottish Government http://scotland.gov.uk/Topics/ArtsCultureSport/arts/CulturalPolicy/workinggroup/Eve $\underline{\text { nts }}$

Scott, J. (2000). 'Rational Choice Theory' in Browning, G., Halcli, A., and Webster, F, (eds) Understanding Contemporary Society: Theories of The Present, London: Sage Publications

Selwood, S. (2002a). Measuring Culture. Spiked, http://www.spikedonline.com/Articles/00000006DBAF.htmaccessed 02.01.11

Selwood, S. (2002b). 'The politics of data collection: gathering, analysing and using data about the subsidised cultural sector in England', Cultural Trends, 47, 13-97 
Selwood, S. (2001). The UK cultural sector: profile and policy issues, London, PSI

Selwood, S. (2006). 'Unreliable evidence: the rhetoric's of data collection in the cultural sector', in Mirza M. (ed) Culture Vultures: how government policy is damaging the arts, London: Policy Exchange article

Sutton, R. (1999) The Policy Process: An Overview, London: Chameleon Press Ltd, http://www.eldis.org/vfile/upload/1/document/0708/DOC7279.pdf, accessed 15.11.10

Widdop, P. and Cutts, D. (2011). Cultural Consumption in Scotland: Analysis of the Scottish Household Survey Culture Module, Edinburgh: Scottish Government Social Research, http://www.scotland.gov.uk/Publications/2011/02/23102413/0 accessed $16 / 03 / 11$

Williams, R. (1981). Culture, Great Britain: William Collins \& Co 